taken bDMARDs \pm sDMARDs had significantly less PsA activity compared to those who had taken other types of treatment (table 1).

Abstract THU0305 - Table 1

\begin{tabular}{|c|c|c|}
\hline Parameters & bDMARDs & other therapy \\
\hline DAS28 & $1.8[1.8 ; 4.2]^{*}$ & $3.4[2.8 ; 5.1]$ \\
\hline CRP & $1.3[0.9 ; 7.9]^{*}$ & $6[2.5 ; 17.8]$ \\
\hline Pain, VAS & $20[13 ; 50]^{*}$ & $30[30 ; 60]$ \\
\hline PGA, VAS & $30[17 ; 60]^{*}$ & $40[30 ; 60]$ \\
\hline PhGA,VAS & $30[10 ; 50]^{*}$ & $38[30 ; 60]$ \\
\hline SJC & $1[0 ; 5]^{*}$ & $1[0 ; 8]$ \\
\hline TJC & $1[0 ; 2]^{*}$ & $1[0 ; 6]$ \\
\hline p $\leq 0.05$, U-test & &
\end{tabular}

Conclusions: MDA was seen in $21 \%$ of PsA pts in routine care but starting bDMARDs has a significantly higher probability of reaching MDA in most cases despite duration of treatment.

Disclosure of Interest: None declared

DOI: 10.1136/annrheumdis-2018-eular.2695

\section{THU0306 CLINICAL SPECIALTY SETTING AS A DETERMINANT FOR DISEASE MANAGEMENT IN PATIENTS WITH PSORIATIC ARTHRITIS: RESULTS FROM LOOP, A CROSS-SECTIONAL, MULTI-COUNTRY OBSERVATIONAL STUDY}

W.-H. Boehncke ${ }^{1}$, R. Horváth ${ }^{2}$, E. Dalkiliç ${ }^{3}$, S.A.L. Lima ${ }^{4}$, M. Okada ${ }^{5}$, M. Hojnik ${ }^{6}$, F. Ganz ${ }^{7},{ }^{8}$ E. Lubrano. ${ }^{1}$ Geneva Univ. Hospitals and Univ. of Geneva, Geneva, Switzerland; ${ }^{2}$ Univ. Hospital Motol, Prague, Czech Republic; ${ }^{3}$ Uludağ Univ. Sch. of Med., Gorukle, Bursa, Turkey; ${ }^{4}$ ABC Med. Sch., Santo André, Brazil; ${ }^{5}$ St. Luke's International Hospital, Tokyo, Japan; ${ }^{6}$ AbbVie, Ljubljana, Slovenia; ${ }^{7}$ AbbVie AG, Baar, Switzerland; ${ }^{8}$ Univ. of Molise, Campobasso, Italy

Background: Evidence suggests that timely and effective management can improve long-term outcomes in patients (pts) with psoriatic arthritis (PsA); however factors influencing treatment management decisions are not well understood.

Objectives: To evaluate the association between the clinical specialty setting and time from inflammatory musculoskeletal symptom onset to PsA diagnosis and to different management steps in pts with a diagnosis of PsA.

Methods: LOOP is a large cross-sectional, multi-centre, observational study conducted in 17 countries across Western and Eastern Europe, Latin America, and Asia. Adult pts ( $\geq 18$ years) with a suspected or an established diagnosis of PsA routinely visiting a rheumatologist (rheum), dermatologist (derm) or non-rheum/ non-derm site were eligible to participate in this study. Each enrolled patient in the study was assessed by both rheum and derm. Main endpoints assessed were time from inflammatory musculoskeletal symptom onset to PsA diagnosis, time from PsA diagnosis to first csDMARD and to first bDMARD, and time from first cSDMARD to first bDMARD.

Results: Of the 1483 pts enrolled in this study, 1273 pts with a confirmed diagnosis of PsA were included in this analysis. A majority of pts were recruited by rheums $(671,52.7 \%)$, followed by derms $(541,42.5 \%)$, physiatrists $(36,2.8 \%)$, and other specialties $(25,2.0 \%)$. PsA was first suspected by a rheum in 726 $(57.0 \%)$ pts and by a derm in 541 pts $(42.5 \%)$. Pt demographics and disease characteristics were mostly comparable between rheum and derm settings. Current disease activity and disease burden of patients with PsA categorised by clinical specialty are shown in table 1. Disease activity was higher in PsA pts in derm setting compared with rheum setting. The timing of different disease management steps by clinical specialty is reported in table 2. The mean time from symptom onset to PsA diagnosis was 24 months (mo) in rheum setting and 1 mo longer for derms. In rheum and derm settings, the mean time from PsA diagnosis to first csDMARD were 11 and 25 mo, respectively; whereas the mean time to first bDMARD were 52 and $55 \mathrm{mo}$, respectively. The mean time from first csDMARD to first bDMARD was 42 mo for rheums; while it was 3 months shorter for derms.
Abstract THU0306 - Table 1. Baseline Characteristics and Current Disease Activity and Disease Burden by Clinical Specialty in Patients with PsA from LOOP Study

\begin{tabular}{|c|c|c|c|}
\hline Characteristic/Measures & $\begin{array}{l}\text { Rheum } \\
(\mathrm{N}=726)\end{array}$ & $\begin{array}{c}\text { Derm } \\
(\mathrm{N}=541)\end{array}$ & P.value* \\
\hline Age, years & $51.1(12.9)$ & & 646 \\
\hline Gender, mate, $n(\%)$ & $375(51.7)$ & 270 (49.9) & \\
\hline Weight, kg & $77.3(16.4)$ & $77.7(17.1)$ & .708 \\
\hline$B M 1, k g / m^{2}$ & $27.4(5.5)^{\circ}$ & $27.4(5.3)$ & 962 \\
\hline TJCEB & $6.0(10.1)^{6}$ & $8.5(12.6)^{\circ}$ & $<.001$ \\
\hline & $2.2(4.3)^{\prime}$ & $3.2(6.2)^{2}$ & .001 \\
\hline Dactylits count & $0.4(1.3)^{x}$ & $0.8(2.6)^{y}$ & $<.001$ \\
\hline Tender entroseal points & $0.8(1.7)$ & $1.5(2.6)^{x}$ & $<.001$ \\
\hline DAPSA & 19.4 (24. 0y & $239(30.9)$ & .017 \\
\hline DAS28 & $2.8(1.3)^{\circ}$ & $29(1.5)^{\circ}$ & \\
\hline MDA, $\cap(\%)$ & $309(46.7)^{\circ}$ & $186(39.2)^{\circ}$ & .012 \\
\hline PGA & $3.3(2.6 \gamma$ & $4.4(2.7)$ & $<.001$ \\
\hline BSA (\%) & $6.6(11.3)^{\circ}$ & $13.1(19.7)^{4}$ & $<.001$ \\
\hline Psoriatic nall count & $4.0(5.5)^{\prime}$ & $5.3(6.3)^{\circ}$ & $<.001$ \\
\hline $\mathrm{HAO}-\mathrm{OI}$ & $0.7(0.7)^{2}$ & $0.7(0.7)^{*}$ & .783 \\
\hline SF IV PCS & $43.0(10.6)^{x}$ & $42.6(10.1)^{y}$ & 544 \\
\hline SF 1222 MCS & $44.9(10.5)^{x}$ & $44.8\left(12.1 y^{y}\right.$ & 803 \\
\hline WPAI.PSA TWPI (\%) & $30.1(30.2)^{z}$ & $29.5(31.7)^{20}$ & \\
\hline WPAI.PSA TAI (\%) & 35.0 (29.8y & $39.2(31.4)^{000}$ & .017 \\
\hline DLOI & $5.3(6.2)^{6}$ & $7.6(7.2)^{\infty}$ & $<.001$ \\
\hline \multicolumn{4}{|c|}{ 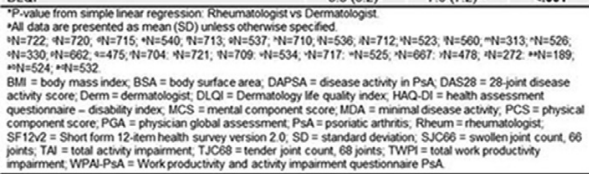 } \\
\hline
\end{tabular}

Abstract THU0306 - Table 2. Timing of Disease Management Steps by Clinical Specialty in Patients with PsA from LOOP Study

\begin{tabular}{|c|c|c|c|}
\hline Duration in months, Mean (SD) & Rheum & Derm & P-value* \\
\hline $\begin{array}{l}\text { Time from inflammatory musculoskolotal } \\
\text { symptiom onset to PsA diegnosis' }\end{array}$ & $23.6(70.7)$ & $24.9(72.1)$ & .747 \\
\hline Time from PSA diagnosis to first CSDMARD & $10.7(59.4)$ & $25.2(93.9)$ & .004 \\
\hline Time from PSA di & & & .715 \\
\hline Time from first CSDMARD to first DOMARD' & $42.4(62.7)$ & $39.1(63.5)$ & .556 \\
\hline \multicolumn{4}{|c|}{ 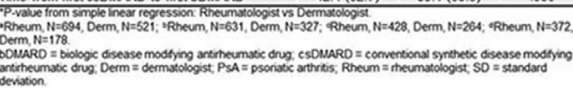 } \\
\hline
\end{tabular}

Conclusions: Although the duration from symptom onset to PsA diagnosis was similar between rheum and derm setting, there were differences in the timing of introduction of different DMARD classes. Notably, mean time to first csDMARD was significantly shorter in rheum setting. PsA pts in derm setting had significantly higher disease activity. These data lend further support to the need for rheumderm collaborative approach to optimise management of pts with PsA.

Acknowledgements: AbbVie funded the LOOP study, contributed to its design, and participated in data collection, analysis and interpretation of the data, and in writing, review, and approval of the publication. AbbVie and the authors thank all study investigators for their contributions and the patients who participated in this study. Medical writing was provided by Deepa Venkitaramani, PhD, of AbbVie. Disclosure of Interest: W.-H. Boehncke Grant/research support from: Abbvie, Biogen Idec, Celgene, Covagen, Galderma, Janssen, Leo, Lilly, MSD, Novartis, Pantec Biosolutions, Pfizer, and UCB, Consultant for: Abbvie, Biogen Idec, Celgene, Covagen, Galderma, Janssen, Leo, Lilly, MSD, Novartis, Pantec Biosolutions, Pfizer, and UCB, Speakers bureau: Abbvie, Biogen Idec, Celgene, Covagen, Galderma, Janssen, Leo, Lilly, MSD, Novartis, Pantec Biosolutions, Pfizer, and UCB, R. Horváth Grant/research support from: AbbVie, MSD, Novartis, Pfizer, and UCB, Consultant for: AbbVie, MSD, Novartis, Pfizer, and UCB, Speakers bureau: AbbVie, MSD, Novartis, Pfizer, and UCB, E. Dalkiliç Grant/ research support from: AbbVie, Speakers bureau: AbbVie, MSD, Roche, Pfizer, and UCB, S. Lima Consultant for: Abbive, BMS, and Janssen, Speakers bureau: Abbive, BMS, and Janssen, M. Okada Grant/research support from: AbbVie Japan, Ayumi Pharmaceutical, Eli Lilly and Company, Mitsubishi Tanabe Pharma, and Ono Pharmaceutical, Consultant for: AbbVie Japan, Ayumi Pharmaceutical, Eli Lilly and Company, Mitsubishi Tanabe Pharma, and Ono Pharmaceutical, Speakers bureau: AbbVie Japan, Ayumi Pharmaceutical, Eli Lilly and Company, Mitsubishi Tanabe Pharma, and Ono Pharmaceutical, M. Hojnik Shareholder of AbbVie, Employee of: AbbVie, F. Ganz Shareholder of: AbbVie, Employee of: AbbVie, E. Lubrano Grant/research support from: AbbVie, Celgene, Janssen, MSD, Novartis, and Pfizer, Consultant for: AbbVie, Celgene, Janssen, MSD, Novartis, and Pfizer, Speakers bureau: AbbVie, Celgene, Janssen, MSD, Novartis, and Pfizer

DOI: 10.1136/annrheumdis-2018-eular.2004 